\section{Historiar la Arquitectura medieval. Intersecciones epistemológicas de la Historia del Arte y la Arqueología de la Arquitectura}

\section{Writing the history of Medieval architecture. Epistemological junctions of Art History and Archaeology of Architecture}

\section{Gerardo Boto Varela*}

Universitat de Girona

Artemio M. Martínez Tejera

Universidad Autónoma de Madrid

\section{Resumen}

Este artículo pondera la situación actual de la Historia del Arte ante el estudio de la arquitectura histórica tardoantigua y medieval. Se reflexiona sobre la legítima reivindicación de la Arqueología de la Arquitectura, de su solvencia científica. Se discute en qué medida ese proceso ha prosperado, en parte, paralelamente a la simplificación de las bases conceptuales de la Historia del Arte. Sin justificación, algunos siguen tachándola hoy de discurso idealista y tipológico, como si sus presupuestos fueran aún decimonónicos.

Como es lógico, el análisis e interpretación «arqueológicas» de un edificio, o «yacimiento vertical», no proporciona todas las respuestas sobre las causas eficientes -históricas e ideológicas- que lo motivaron. La Historia del Arte puede contribuir a incrementar ese arsenal de respuestas. Sin embargo, su ausencia en muchos encargos administrativos está privando a la sociedad de un conocimiento eficiente y relevante. La tarea del historiador del arte ha sido subestimada. Se le reprocha actuar como un esteta epidérmico, aún cuando resulta insobornable su compromiso con el legado patrimonial de esta sociedad. Arqueólogos e Historiadores del Arte compartimos en ocasiones un mismo objeto de estudio. Sin embargo, no es inusual que la relación se establezca en términos de confrontación, y casi beligerancia, por cuotas de autoridad académica y capacidad de actuación. ¿Hacia qué horizonte queremos dirigirnos los profesionales y académicos de la arquitectura histórica?

Palabras claves: España, Arquitectura Medieval, Disciplinas Académicas, Epistemología.

\section{Abstract}

This article offers a point of view about the role that the History of Art is currently playing in the study of the Architecture of Late Antiquity and Middle Ages. It is discussed how the Archaeology of Architecture has tried to claim scientific competence over this topic of study partly by simplifying the theoretical foundations of the Art History. This academic field has been somewhat reduced exclusively to the category of an idealist, typological discourse, as if based in old-fashioned assumptions coming from 19th-century academic traditions.

The analysis and interpretation of a building as a vertical archaeological site does not provide all the answers about its historical and ideological motivations. The Art History may help to obtain more answers. The absence of the Art Historian in administrative commissions deprives society of an efficient and relevant knowledge. The art historian's task has been systematically underestimated as that of an epidermic aesthete, even when his compromise with the heritage legacy of our society is incorruptible. Architectural Archaeologists and Architectural Historian share a same topic, but the terms of the relationship among both of them are those of a dispute to obtain quotas of power and intervention. Which horizon are professionals and academics of historical architecture heading for?

Keywords: Spain, Medieval architecture, Academic Disciplines, Epistemology.

* gerardo.boto@udg.edu; artemio.martinez@uam.es
Es un secreto a voces que la relación entre Historia del Arte (HA) y Arqueología de la Arquitectura (AA) ${ }^{1}$ en España son escasas y raramente fecundas, con actitudes integradoras atribuibles a profesionales individuales antes que a colectivos. Esta tibieza, lejos de restringirse a la academia española, se manifiesta de modo tanto o más palmario en otros países (Brogiolo, 1988; idem, 2002. Azkarate, 2008). En la práctica, son contados - $y$, por ende, meritorioslos casos en que se puede encontrar a historiadores del Arte y arqueólogos trabajando, de manera complementaria, en un yacimiento o en un templo. Tampoco resulta común hallar a historiadores del arte compartiendo, y menos desempeñando, un encargo administrativo (sea autonómico o local) de gestión y puesta en valor del patrimonio arquitectónico, aunque existen ejemplos meritorios - como los llevados a cabo desde el Observatorio del Patrimonio Histórico Español o desde la Fundación del Patrimonio Histórico de Castilla y León- que constituyen excelentes elementos de referencia. Con demasiada frecuencia, y esto es aún más clamoroso, los historiadores del Arte ni siquiera forman parte de los equipos que redactan y despliegan los planes directores de los grandes templos. Intentaremos argumentar que esta carencia va en severo detrimento de nuestro patrimonio, de su óptimo conocimiento y de una conservación y divulgación más eficiente.

Acometemos nuestro discurso, en primer lugar, partiendo de un estimulante, oportuno y hasta necesario artículo recientemente publicado en esta misma revista por nuestro colega el historiador del arte Fernando Arce Sainz (Arce Sainz, 2009). Arce explicita y expone nítidamente un debate académico y una tensión profesional que, primero de modo tácito pero después de manera cada vez más explícita, se ha ido enfatizando en los últimos lustros. Se trata de un debate que el autor conoce de primera mano y sobre el que puede opinar dado que trabaja en un entorno profesional básicamente arqueológico.

Constituyen un segundo acicate para nosotros los intensos debates académicos mantenidos reiteradamente con otros historiadores e historiadores del Arte desde hace años sobre el papel, las responsabilidades y los retos actuales de la HA. A nuestro juicio, y al de numerosos colegas, no deberíamos seguir posponiendo la convocatoria de un debate académico y profesional en torno a las bases conceptuales y a la proyección sociolaboral de la

${ }^{1}$ Acaso, no sea suficientemente conocido cuándo comenzó a emplearse este sintagma nominal. Aunque su significado pretérito difería del actual, una de las primeras ocasiones en que apareció impreso fue el 3 de diciembre de 1882 en The New York Times. 
HA, de manera particular en lo relativo al estudio de la arquitectura histórica, más allá de la figura del gestor cultural. Pero esta cuestión —esperamos- se abordará en otro foro. Aquí nos limitamos, mucho más modestamente, a reflexionar sobre la relación entre la HA y la AA. Pretendemos, en definitiva, contribuir a repensar los argumentos de un debate que, por diferentes razones, especialistas de una y otra esfera han puesto en sordina. Aunque la tarea ya ha sido abordada severa y puntualmente por algún arqueólogo e historiador, su repercusión ha sido limitada (Díaz-Andreu, 1995), quizá por la franqueza y rotundidad de sus argumentos (Ortega y Villargordo, 1999).

Entendemos atinadas muchas de las valoraciones de Arce, como también las de Ortega y Villargordo. Sus respectivos trabajos reflexionan sobre la construcción metodológica de la disciplina arqueológica y su institucionalización académica. Llegan a la conclusión de que la Arqueología (ARQ) lleva tiempo propendiendo hacia una considerable "promiscuidad» epistemológica, de suerte que no existe ningún 'Área de conocimiento' exclusiva de la arqueología. Ni sus métodos le son propios, ni hay campo teórico alguno que pueda adjudicarse para sí sin entrar en disputa con otras disciplinas (Ibid.). Desde la ARQ se intentó revertir la imputación adoptando una "posición disciplinar intermedia». Como cualquier otra disciplina, la ARQ y otras subdisciplinas como la AA ha generado un nuevo léxico no exento de silogismos y tecnicismos. Se ha intentado con éxito justificar la autosuficiencia de sus procedimientos y la especificidad de sus modelos interpretativos. La enfática concentración en los procesos de producción material, dentro de un marco amplio de una historia económica y social, permite a la AA distanciarse de otros saberes humanísticos basados en las fuentes textuales -desmarcarse de manera muy enfática de la Historia del Arte- para adscribirse, en cambio, al ámbito de las ciencias sociales y experimentales.

En las últimas décadas, la nítida divergencia metodológica entre la HA y la AA se viene justificando como la ineluctable consecuencia de su disparidad epistemológica y de objetivos. ¿Qué pretende documentar la AA y qué la HA? ¿Dónde focalizan respectivamente su atención y qué logran conocer del objeto de estudio compartido? ¿Se solapa el conocimiento de una disciplina al de la otra? Más aún, ¿la AA lo suple y lo optimiza, y en tal caso, conforme a qué parámetros?

La AA surge del convencimiento de que se puede y se debe realizar Arqueología por encima de la "cota 0" (perspectiva y estado de la cuestión sobre la AA en
Mañana, Blanco, Ayán, 2002: 15-16). Esa fue una de las novedades académicas con las que se encontraron los jóvenes historiadores del arte que, a finales de los años 80 del siglo XX, emprendían una carrera investigadora. Fue entonces cuando algunos arqueólogos españoles, inspirados por sus colegas italianos, comenzaron a ocuparse de los paramentos conservados por encima de los pavimentos. $Y$ lo hicieron aplicando técnicas analíticas novedosas junto a otras tradicionales, como la tipología o la analogía (Quirós Castillo, 2002: 28). Al mismo tiempo, fueron discriminándose diversas "Arqueologías». Empezaron a multiplicarse las actuaciones de la «arqueología involuntaria» (Ibid: 29), de la arqueología de gestión o empresarial. La Arqueología salió del aula para introducirse en el mundo empresarial y el sistema productivo. El Historiador del Arte no dio ese mismo salto y permaneció en el dominio de la investigación académica.

Algunos historiadores del arte pensaron que la Arqueología y la tecnología podía incrementar la eficiencia de la tradicional datación por tipologías y estilos y la lectura de paramentos, hasta entonces realizada por la HA y la Historia de la Arquitectura por exploración óptica. La HA y la «Historia de la Arquitectura» conciliaron durante generaciones una "Historia de los Estilos» con una «Historia de la Construcción» (Cabrera, 1983). Fue en 1987 cuando se explicó cómo incrementar la comprensión del edificio mediante la puesta en práctica del método arqueológico. Ya entonces requirió la presencia en las excavaciones de un equipo profesional compuesto por arqueólogos, evidentemente, además de peones, dibujantes, topógrafos, fotógrafos, restauradores y arquitectos (Caballero Zoreda 1987: 25 y ss.). La disciplina de la HA quedaba excluida.

En relación con la producción edilicia tardoantigua y altomedieval, ambas perspectivas han dibujado panoramas muy diferentes (Caballero et alii, 2003: 84 vs. Martínez Tejera, 2003: 53 y ss.). Sin embargo, más allá de cuestiones específicas, queda patente que las vías disciplinarias distintas de la AA y la HA confluyen en sus objetos de estudio y pueden alcanzar conclusiones análogas. No obstante, resultará provechoso constatar de qué otros asuntos informan cada una de esas dos especialidades. La HA, como intentaremos detallar más adelante, procura pensar desde los criterios de usos de los recintos, de la poliédrica funcionalidad de los mismos y desde la condición social de sus protagonistas.

Desde el momento en que la AA comenzó a pergeñar un «método para el análisis estratigráfico» o "análisis arqueológico» (Caballero Zoreda, 1995. Parenti, 1995. 
Caballero - Fernández, 1997), el arqueólogo de la arquitectura pasó de excavar un yacimiento a interpretarlo «arqueológicamente». Ciertamente, el planteamiento fundacional y nuclear de la AA se condensa en el reconocimiento de que un edificio histórico constituye un «yacimiento vertical». La óptica de la AA se superpuso —más aún, comenzó a suplantar- a las propuestas formuladas desde los "estilos arquitectónicos», ese recurso pedagógico que durante décadas resultó adecuado para posicionar la creación de las obras en un tiempo y un espacio, aunque razonablemente criticado en el seno de nuestros departamentos (Bango, 1996). Algunos investigadores de la arquitectura se pronunciaron por la imposición o sustitución antes que por la colaboración (Pierotti - Quirós, 2000; Quirós Castillo, 2002). Visto en perspectiva, nada tiene de extraña esta estrategia porque, para justificar su presencia y autonomía disciplinar distintos «pactos o luchas unen o enfrentan a la arqueología con otras perspectivas, dentro o fuera de la misma disciplina arqueológica, y con otros profesionales» (Ortega y Villargordo, 1999: 8).

La situación actual queda sobradamente explicitada con lo apuntado hasta esta línea. A pesar de ello, una amplia fracción de los historiadores del arte —refractarios, autocomplacientes y acaso ensimismados - han continuado preguntándose retóricamente durante los últimos quince o veinte años si la aportación de la AA resultaba en verdad trascendente para lograr un auténtico «conocimiento social y artístico» del edificio. Para nosotros no hay duda de que las aportaciones de la ARQ y de la AA son sustantivas y estimables, dado que se ha esforzado en racionalizar y tipificar los recursos y los parámetros con los que un edificio o un conjunto arquitectónico puede y debe ser examinado y estudiado. Nos resulta igual de nítido que la AA se ha afanado en prospectar e incrementar la cientificidad del estudio de la Arquitectura Tardoantigua y Altomedieval.

Los historiadores del arte debemos aprender no sólo nuestros intrínsecos procedimientos de análisis (centrados en argumentos que exploran desde la cultura visual a la iconografía de la arquitectura de un periodo), sino también a interiorizar los que otras disciplinas colindantes ponen en juego. Llevamos mucho tiempo haciéndolo con la epigrafía, la literatura o la numismática, por poner algún ejemplo clásico, pero conviene complementar nuestra formación atendiendo también a la arqueología de la edificación, como es habitual en Francia desde hace décadas (Arlaud y Burnouf, 1993; Au fil, 1997; Reveyron, 2000; Id. 2005; Sapin, 2002).

\section{¿HISTORIA DEL ARTE = HISTORIA DE LOS ESTILOS?}

Hace tres décadas que la «Teoría de los Estilos», vector definitorio de la más inveterada tradición discursiva de la HA, es desdeñada por muchos arqueólogos por considerarla insolvente, inconcreta, subjetiva y obsoleta desde su prisma metodológico. No obstante, y a decir verdad, mucho antes que para los arqueólogos, la perspectiva estilística resultó insatisfactoria para una legión de historiadores del arte. En otras palabras, la crítica se había producido ya con anterioridad en el seno de la propia HA (Bango, 1996).

Frente a los análisis estilísticos, tildados de "preestratigráficos» por la AA e imputados al conjunto de la HA como si se tratara de una propensión congénita e irremediable, si no de un recalcitrante pecado original, la AA afirma aplicar una nueva «metodología para la observación y registro de los edificios históricos» (Arce Sainz, 2009: 24) que prima la «filología estratigráfica como criterio fundamental de análisis de la arquitectura» (Quirós Castillo, 2002: 28). Volveremos sobre ello, pero conviene dejar asentado ya que la AA persiste en su interés en reducir la HA a la Historia de los Estilos, cuando hace décadas que nuestra disciplina ha superado esa perspectiva. De hecho, desde el siglo XIX, los historiadores del arte hemos procurado justificar la existencia del edificio en el contexto histórico que lo alumbró.

Acaso esta anacrónica imputación se derive de las fuentes italianas que proveen a la AA que se practica en España. Ciertamente si alguna academia europea continúa cultivando aún hoy un acendrado análisis formalista y estilístico esa es la italiana, cuyo prestigio morelliano resulta incuestionable por más que otras historiografías nacionales se desmarquen de ese tenor. Para un historiador del arte actual tener que soportar la amonestación de que nuestra disciplina no ha rebasado el estadio de la gramática de los estilos -como si nos obstináramos en una suerte de formulismo filológico, aunque con dimensión visual- equivale a que un arqueólogo fuera reconvenido por no haber descubierto aún el método estratigráfico.

La agria pero inequívoca realidad es que para una parte sustancial de la AA resulta reconfortante considerar que la HA continúa siendo una práctica taxonómica que reconoce, tipifica y clasifica molduras, arcos, capiteles o pliegues a partir de sus rasgos formales. Desde ese punto de vista, se tasa al historiador del arte como un taxidermista que se recrea en la epidermis de la realidad y de las fábricas. En otras palabras, un especialista con una mirada superficial y unos procedimientos banales. Desde hace un par de décadas, la HA tiene que tolerar las censuras de aquellos 
investigadores que, desidiosos por conocer su verdadera dimensión epistemológica, optan por conceptuarla como una suerte de taxonomía de lo ornamental. En consecuencia, y sin pretender generalizar, muchos la suponen una práctica despojada de la menor autoridad científica para contribuir al estudio y al conocimiento de los templos y palacios, y menos aún para opinar o sufragar las propuestas de intervención, gestión y comprensión del bien patrimonial arquitectónico. Digámoslo sin ambages: llegado a ese punto no se confrontan fortines académicos, sino cuotas de poder.

En una aplaudida valoración, Carandini tachaba a los arquitectos restauradores que se distanciaban de la arqueología como a estetas que leían las constelaciones de los elementos constructivos como astrólogos antes que como astrónomos (Carandini, 1987). La AA concibe, reivindica y explica la arquitectura como una estructura desnuda, en la que es legible la verdad mecánica de las fábricas. En esa divergencia entre la materialidad de la construcción y la idealidad del proyecto, los historiadores del arte presuntamente permaneceríamos como diletantes, embelesados en las superficies y en los tatuajes de los edificios, sin recabar nada que subyazca a su piel. Intentaremos desmentir lo erróneo de esta valoración, pero antes de ello valdrá la pena considerar si el estudio de la arquitectura, al pasar del foco del esteta a la camilla del forense - en el intento de explicar mejor cómo era o cómo se intervino diacrónicamente en su concreción física-, ha logrado desvelar para qué y para quién se operó y alteró.

\section{ÁREA RESTRINGIDA: SÓLO PERSONAL AUTORIZADO}

De una serie de premisas falsas se deriva una exclusión progresiva pero sistemática de las plataformas de estudio e intervención en las fábricas antiguas. Alguien decidió hace décadas que somos culpables de recrearnos en nuestro pecado original —que, claro está, deviene en pecado capital - y debemos subsistir relegados al margen de las actuaciones administrativas y de la atribución de presupuestos. Nuestra visibilidad social ha quedado más mitigada -a efectos prácticos, subordinada- en relación con el estudio arquitectónico, a pesar de que la HA sí es un grado universitario generalizado. Y todo ello acaece porque, presuntamente, no poseemos ni aspiramos a poseer otra vocación que redundar en nuestro discurso tautológico, cegado a las evidencias materiales.

Una crítica de ese tenor resulta desproporcionada y, en muchísimos casos, injustificada. En cambio, sí debemos asumir nuestra culpabilidad en el plano estratégico: no hemos sabido explicarnos de modo adecuado y no lo hemos hecho en forma suficiente en foros científicos de otras disciplinas, como esta revista, a la que agradecemos sinceramente su generosidad y amplitud de miras. Con todo, sería ingenuo considerar que no somos requeridos en esos foros sólo por nuestras deficiencias discursivas.

Entre tanto, la «Historia de la Construcción», a cargo de arquitectos restauradores y en alguna ocasión arquitectos-arqueólogos, formuló un examen sistemático de la materialidad de muros y cubiertas (Cabrera, 1983). Su posterior aproximación a la AA resulta elocuente de su aspiración a conjugar procedimientos y perspectivas. Una y otra comparecen profesionalmente en los mismos escenarios y ejercen sus cometidos desde tesituras análogas, de suerte que se reconocen recíprocamente y se otorgan de modo bilateral el marchamo de «actividades científicas»: «así, una disciplina de aplicación corriente para el control de calidad de la edificación se ha convertido en una herramienta científica» (Vela Cossío, 2007). No es inocua la consideración de que la «Historia de la Construcción» propende al diagnóstico, se afana en reconocer el historial de patologías de una fábrica, se esfuerza en explorar su sintomatología y, en consecuencia, predice un pronóstico y prescribe un tratamiento paliativo. La AA, por su parte, asevera ante la Historia de la Construcción que los métodos y herramientas de los arqueólogos son los idóneos para perfilar el historial patológico del edificio, en lo que debe reconocerse como un verdadero éxito en la promoción de su caracterización epistemológica. La delimitación conceptual de la arqueología requiere de alianzas profesionales con unos sectores, del mismo modo que procura el distanciamientos de otros. De manera un tanto eufemística, se afirma que «los arquitectos restauradores han visto en este nuevo marco administrativo una oportunidad para integrar de forma rigurosa las informaciones estratigráficas, entendiendo la acción del arqueólogo como una ventaja y no como un inconveniente» (Quirós Castillo, 2002: 29). En quince años, los arquitectos han permutado la astrología por la astronomía. Esta corrección debe ser celebrada, y no porque la AA haya extraído algún beneficio, sino porque gracias a esa mudanza el saber histórico ya está salvaguardado.

La AA y la Historia de la Construcción, diligente y legítimamente, procuran afinar sus dictámenes para que éstos resulten cada vez más precisos, entendido este concepto no sólo en el sentido de certero sino también en el de necesario. De este modo, hoy por hoy, en nuestro país la AA y la Historia de la Construcción se posicionan y hacen guardia en la antesala de la restauración. Los responsables de los dictámenes y las sinecuras solicitan sus informes por 
su inapelable solvencia y por su meritoria capacidad para promocionarlos.

Afirma Arce, en sintonía con otros autores (Vela Cossío, 2007: 164 y ss.), que la «lectura de paramentos» permite reconocer «microhistorias» y que desde la AA el edificio «es estudiado y entendido de forma dinámica como escenario plurisecular y de acontecimientos históricos que le han afectado a él y solo a él, dando como resultado una biografía constructiva detallada única e intransferible» (Arce Sainz, 2009: 24). Durante décadas, la AA se ha apremiado en demostrar que posee una capacidad singular para redactar esta reseña biográfica de la fábrica histórica, concebida como un «organismo vivo» en incesante evolución.

Esta continua metamorfosis queda cicatrizada en muros y cubiertas. Mediante la «lectura de paramentos», la HA ha leído los «tiempos parciales» que revelan la secuencia consecutiva de las fases o los periodos históricoconstructivos. Ante ello, la AA ha dado a entender abiertamente que nuestra metodología y el umbral de minuciosidad restringen la pericia de nuestros rastreos y lastran la «lectura de paramentos». Frente a esa aproximación bienintencionada pero imperita de la HA, la AA reivindica que existe un único cauce para desplegar un análisis científico ante un yacimiento vertical -lo que vulgarmente los miopes historiadores del arte venimos llamando «monumento" - y que no es otro que el de la matriz Harris (Harris, 1991). Sin duda, la sistematización y jerarquización de relaciones en el entramado de episodios constructivos y huellas de intervención de una fábrica resulta una aportación sustantiva y medular de la matriz Harris, herramienta efectiva para articular cronologías relativas (Parenti, 1996). Se ha detallado (Mañana, Blanco y Ayán, 2002: 19-20) que la AA suplementa esta lectura con un análisis de materiales (aunque muchas veces lo efectúan otros especialistas científicos), el examen de la documentación escrita (como los historiadores), con la georreferenciación del edificio (como los topógrafos) y la cronotipología de aparejos y elementos singulares (porque esos elementos, al parecer, sí resultan susceptibles de ser tipologizados. Cfr. Gabrielli, 1996. Quirós Castillo, 1996).

A tenor de esto último, se diría que la $\mathrm{HA}$ cae en el pecado de la tipología, aunque el yerro se agrava al encontrarse encorsetada entre la taxonomía y la presunción. ¿Habrá algún modo de eludir esas férreas lindes? Sin duda, queda mucho que aprender en el diagnóstico material. Pero resulta falible imputar a la HA que se ha cegado - a modo de una sinagoga académica del siglo XXI- y no vislumbra las vías de la Nueva Ley. El método arqueológico afirma que "está mejor preparado para fechar y comprender el edificio como un documento histórico, incluyendo en lo histórico desde el aspecto cronológico a la interpretación social y estética, pero ello no debe hacer que invalidemos los otros métodos. Lógicamente aquellos caerán en desuso (...) si es que son menos útiles que los nuevos instrumentos pero, aún así, es posible que algunas de sus habilidades sigan siendo válidas» (Caballero Zoreda, 1997: 307). Nos tememos, en realidad, que si la HA palidece no es por sus procedimientos de discriminación e interpretación de momentos constructivos. Hemos podido constatar, a través de la casuística de distintos colegas, que la dificultad estriba en conseguir que las credenciales de la HA sean calibradas en toda su extensión por otros gremios.

Seamos francos. Resulta tan injustificado como abusivo que se difunda la estimación simplista de que los historiadores del arte hoy, como hace medio siglo, aún nos limitamos a registrar los motivos ornamentales o el léxico arquitectónico y, en el mejor de los casos, a explorar y leer los elementos estructurales. Lo cierto es que no nos circunscribimos a este examen, pero aunque así fuera, ocurre que la lectura estratigráfica de la ARQ y de la AA no siempre provee de informaciones explícitamente más afinadas, provechosas o inequívocas. Es más, en ocasiones la HA ha proporcionado los mismos resultados y con la misma solvencia que el empleo del método «científicoarqueológico» (Martínez Tejera, 2005; Idem, 2010). Tal vez una colaboración entre la Arqueología y la HA, junto con una mayor coordinación por parte de la Administración, hubiera ofrecido otros resultados más precisos sin incrementar el costo. Pero esta cooperación difícilmente tendrá lugar si, ante objeciones bien argumentadas desde la propia Arqueología, un sector de la AA responde que esas son sólo posturas "puntuales y circunscritas de carácter reaccionario" (Quirós Castillo, 2002: 30).

Convencidos de las potencialidades de la colaboración entre una y otra, algunos historiadores del arte hemos decidido incorporar algunos instrumentos y metodologías de la ARQ y AA, como un refuerzo apropiado y fructífero en el análisis del edificio histórico (Martínez Tejera, 1993; Herráez y Teijeira, 2003; Boto Varela, 2009). Estamos reconociendo la posibilidad de que nuestros análisis pueden resultar más eficientes a la luz de las proposiciones técnicas y metodológicas complementarias, de modo particular las llegadas desde la ARQ y desde la AA. Agudizar el análisis y disección de la estructura y configuración material de la fábrica resulta fundamental para trazar una morfogénesis más precisa. Posibilita incluso reconocer las dudas y tribulaciones de los constructores, conforme al 
llamado giro antropológico, que desde hace un par de décadas la HA practica también en la esfera de las imágenes. Será imprescindible, obviamente, que en todos nuestros estudios el análisis no esté mediatizado por interpretaciones previas.

El propósito final de nuestros trabajos es incrementar la excelencia del conocimiento de las fábricas, de sus contextos sociales y de los protagonistas que intervinieron en ellas. Nos interesa específicamente contrastar las razones de los maestros de obras con los requisitos de los promotores y, por ese cauce, optimizar el discurso históricoartístico. Historiar mejor la arquitectura, desde la convergencia de distintos saberes, es el comprometido objetivo que debe guiarnos a todos.

\section{APRIORISMOS Y RECHAZOS}

Cuando un historiador no adscrito a un grupo instituido de AA se acerca a la ARQ parece despertar una instantánea prevención. De hecho, los historiadores e historiadores del arte sólo podemos trabajar con planimetrías detalladas en unas ocasiones y más genéricas otras, acompañadas de memorias de excavación en muchas ocasiones sin imágenes que, con excesiva frecuencia, engrosan sus páginas con introducciones alimentadas por publicaciones anteriores y resoluciones someras de los elementos exhumados o identificados. Desde luego, las dificultades para conocer - no digamos ya para reproducir- algo in situ son mucho mayores. Una lógica aplastante inspira esta circunstancia: se tiende a pensar que el único capacitado para interpretar un yacimiento es aquél que lo excava.

Entretanto, el historiador del arte que estudia arquitectura histórica ya no es dueño del objeto que estudia, si es que lo fue alguna vez. La corrección de este factor en modo alguno es consustancialmente negativo, porque el monumento debe estar a disposición científica y académica de toda la comunidad. Progresivamente, la AA ha ido adquiriendo una posición más confortable con el amparo de la Administración Pública. Con ser ésta una situación cada vez menos infrecuente, importa mucho más explicitar sin ambages una circunstancia vigente. Mientras la Administración no reconozca que los historiadores del arte pueden y deben cumplir una responsabilidad básica en el estudio de la arquitectura histórica -y más abajo razonamos dónde radica esa aportación exclusiva e inevitable- seguirá siendo muy magro el margen de actuación de la HA fuera de las aulas y las editoriales. Esta consecuencia ya ha sido reconocida previamente por otros con claridad meridiana (Ortega y Villargordo, 1999). Por lo mismo, parece ingenuo considerar que se modificarán espontáneamente los meca- nismos administrativos y corporativos que achican la competencia profesional, empañan la necesidad y solvencia del discurso y relegan a la gratuidad — por taxonómica y ornamental - la aproximación de la HA que estudia la arquitectura histórica. Con todo, y por sorprendente que parezca, hay tantos historiadores del arte que constatan cotidianamente este estado de cosas como muchos otros que lo ignoran o lo desdeñan. Una campana de vidrio continúa amparando - o segregando - de la realidad a cuantiosos profesores e investigadores. De esta suerte, y siempre refiriéndonos al estudio de la arquitectura histórica, no se afina al diagnosticar el signo de los tiempos actuales y menos aún al pronosticar qué mecanismos de reactivación e idoneidad deben ser orquestados para adecuar e incrementar la competencia científica y profesional de sus alumnos interesados en esta materia desde el grado universitario de HA. La AA reclamó habilidosa y explícitamente su protagonismo en los protocolos de estudio y restauración de edificios blandiendo bases conceptuales y científicas diferenciadas, hasta que logró empañar las que otros saberes ya poseían de antemano.

\section{LEER, INTERPRETAR, TAL VEZ HISTORIAR}

Para un historiador del arte resulta de particular utilidad que la ARQ pueda llegar a afinar en la atribución fiable de contextos cronológicos mediante su corpus de instrumentos de datación, tanto relativa como absoluta. Evidentemente, los datos suministrados deberán ser contrastados con los que provean otras disciplinas. La nuestra, sin ir más lejos, presta una minuciosa atención a las fuentes escritas, aunque no sólo a ellas. Por eso, procuramos contrastar las reutilizaciones o reempleos de materiales y estructuras preexistentes acreditadas por la documentación con los indicios advertidos en las fábricas. Sin duda, la AA puede llegar a situar correctamente las intervenciones en el tiempo y así «afinar la calibración» (Arce Sainz, 2009: 25). Otros autores ya han indicado, no obstante, que «los problemas surgen cuando se intentan aunar ambos registros (el textual y el arqueológico) en el estudio de la época altomedieval» (Carvajal y De Soto, 2010: 22), una afirmación que, por cierto, nosotros hacemos extensiva al periodo tardoantiguo, época desatendida en su momento por la ARQ. Textos y restos materiales, arqueológicos y monumentales, siguen siendo los dos principales yacimientos de información que proveen a los investigadores que construyen el relato histórico (Arostegui, 1995: 314-398). No obstante, en ocasiones documentos y paramentos entran en contradicciones. Como historiadores del arte, procuramos la «contextualización» de ambas fuentes históricas 
(Moreland, 2001), conscientes de que ni en las fuentes escritas ni en los lienzos murarios se encuentra una verdad incontrovertible e inequívoca. No hay duda, sin embargo, de que elaborar un discurso histórico es tarea que se despliega sobre fuentes escritas, acaso también sobre otras, pero inevitablemente sobre éstas, por más que algún autor critique su peso excesivo en la investigación universitaria (Reveyron, 2005: 22).

Los historiadores del arte, tradicionalmente, conjugamos la documentación textual con el examen de las fábricas, considerando tanto su "estilo» como su funcionalidad, a fin de reconocer los perfiles de una problemática histórica. Por simple dinámica formativa, el historiador del arte está habituado a construir la historia socio-cultural y artística del edificio, leyendo entre otros planos, los «estilos». Por su parte el arqueólogo, se reconoce particularmente interesado y capacitado para estudiar la construcción como objeto en sí (Caballero et alii, 2003: 84). Ni unos ni otros juzgamos que la arquitectura sea un objeto aislado ni que se pueda estudiar de manera aislada. Pongamos un ejemplo. Es muy probable que los paramentos del palacio regio de Toledo en el siglo VII estuvieran ejecutados con una técnica análoga a la iglesia principal de la ciudad. Ante el eventual hallazgo de unas estructuras de ese horizonte cronológico y espacial, será la exploración del área ceremonial, tanto interior como exterior, esto es, la inmediatez a una necrópolis lo que permitirá desvelar la funcionalidad de los restos. Esas respuestas no las puede proporcionar aisladamente la lectura arqueológica de los muros, sino un cúmulo de informaciones, entre las cuales los textos -si existen- resultan primordiales en la discusión y confección del relato histórico, tanto como lo pueden llegar a ser los eventuales hallazgos arqueológicos.

La tarea del arqueólogo no están exenta de algunos condicionantes, según se ha reconocido: «Normalmente se tiende a datar el subsuelo de forma apriorística dependiendo de la idea previa que tenga cada excavador. Si se piensa que la iglesia es, por ejemplo, del siglo VII será «obvio» que los niveles fundacionales, cuando se encuentren, serán tenidos del mismo momento" (Caballero et alii, 2003: 82). Ciertamente, se trata de un proceso que hemos podido acreditar (Martínez Tejera, 2010). Estaremos de acuerdo en que las excavaciones no se deberían abordar sólo para confirmar o desmentir los textos. Ni la información textual debería ser avasallada por la arqueológica, ni la realidad material puede supeditarse a un guión literario preestablecido que esquive los hallazgos materiales. El análisis de los restos materiales y la documentación deben contrastarse para extraer unas valoraciones críticas y verosímiles.
Los juicios previos jamás pueden ser un punto de partida asumible y, sin embargo, resulta palmario que los apriorismos negligentes afectan tanto a la HA como a la ARQ y a la AA. Como historiadores del arte siempre hemos mantenido una postura muy crítica respecto a la infalibilidad de los textos, ya sean documentos, crónicas o epígrafes, aunque este escepticismo no siempre haya encontrado la adhesión de otros colegas.

Entendemos que el examen de las fábricas históricas se enriquece notablemente con la consideración desacomplejada de las aportaciones de la ARQ. La experiencia nos demuestra que, por sí misma, la exploración de la materialidad no puede dar respuesta a todas las preguntas que plantea la excavación de un ámbito tardoantiguo o altomedieval. Desde luego, tampoco está al alcance de la HA, y menos aún si circunscribe su análisis a planteamientos didácticos periclitados. Con todo, aunque el estilo de una obra y las comparaciones formales no resultan enunciados incontrovertibles, como se ha reconocido y reiterado, sí continúan siendo síntomas e indicios estimables. Si a estos indicadores se sumaran los proporcionados por la ARQ y la $\mathrm{AA}$, las perspectivas de análisis se enriquecerían de modo sustantivo y acaso también los resultados. Es cierto que una franca colaboración interdisciplinar en pos de un objetivo común resultará factible sólo si desarbolamos los fortines respectivos, como parodiaba Arce. Nadie debería reconocer en la poliorcética una postura académica. Sin embargo, no estamos reflexionando únicamente sobre competencia científica, sino sobre las cuotas de poder acumuladas para desplegar nuestros principios epistemológicos. Esta perspectiva es la que ha convertido nuestros departamentos en cuarteles y a los doctorandos en fuerzas de choque. Se diría que, más que compartir un objetivo común, competimos por un común objeto de deseo.

\section{TECNOLOGÍA Y ANÁLISIS DE LA ARQUITECTURA}

La ARQ está incorporando cada vez más, en su metodología pero sobre todo en sus análisis prácticos, las nuevas tecnologías. Este factor implica que, progresivamente, sus resultados dependen de otras disciplinas científicas, como la química, la petrología o la dendrocronología, de procedimientos como la mensiocronología (Quirós Castillo, 1996), de técnicas como la termoluminiscencia y de exploraciones proporcionadas desde la topografía y la geomática, como el georradar o los escáneres 3D. El análisis tecnológico, para qué eludirlo, está al alcance de quienes son receptores de dotaciones económicas suficientes y disponen de equipos complejos, pero desde luego y ante todo de los profesionales que estiman que el concurso de estos méto- 
dos es provechoso. La AA, más que otros, los considera adecuados y con frecuencia puede costearlos. No es menos cierto que una parte de la HA no considera imperioso el empleo de recursos tecnológicos, pero aunque lo deseara casi siempre le resultan inasequibles. La mayor o menor familiaridad con esos elementos de exploración y diagnosis, a su vez, repercute hoy en la recepción de solicitudes y consultas para intervenir en el mantenimiento del edificio histórico. Indicaremos a renglón seguido, no obstante, que en algunos proyectos encabezados por historiadores del arte estas exploraciones tecnológicas ya se están llevando a cabo. Así ha sucedido, por citar algún caso, en San Isidoro de León y San Miguel de Escalada en 2008-2009, en La Seu d'Urgell en 2010, y entre los investigadores extranjeros, mencionaremos el caso del proyecto de Peter Klein sobre los claustros de Girona, Sant Cugat y Silos (2008). En otras palabras, el interés y el contacto habitual con ese instrumental y sus modalidades de estudio hoy ya no continúan siendo un coto vedado. Ahora bien, el dominio del arsenal tecnológico por sí mismo nada proporciona. Si no se conocen suficientemente bien todas las circunstancias que caracterizaron al taller de Velázquez, poco importa que se puedan hacer radiografías de las capas subyacentes de los cuadros o análisis mineralógicos de sus pigmentos. Se puede encargar el mapa litográfico de una iglesia, pero si se ignoran los factores históricos y los protagonistas que incidieron en su biografía nada sustantivo podrá concluirse. En esta tesitura, resulta un desafuero que las administraciones que deben velar por la conservación y conocimiento de nuestro patrimonio histórico no requieran con mayor frecuencia la opinión y comparecencia de la HA especializada. Las administraciones públicas, en buena medida, han acrecentado y apresurado el desencuentro de la AA y la HA y la colisión entre sus profesionales.

La actividad arqueológica en un determinado edificio o conjunto arquitectónico —en muy raras ocasiones de investigación - suele venir motivada por actividades de limpieza, conservación y restauración (Arqueología de Gestión) dirigida por un "Arquitecto Restaurador» que infrecuentemente cuenta con la HA como herramienta de trabajo y consulta. El capítulo destinado a actividades arqueológicas sale a pública subasta. Cualquier arqueólogo puede excavar el yacimiento horizontal o vertical, independientemente de su trayectoria y de sus conocimientos respecto al «espacio temporal» sobre el que va a actuar, destruyendo y documentando. No faltamos a la verdad si reconocemos que con asiduidad es la empresa encargada de las obras la que «sugiere» al arquitecto el arqueólogo facultativo. La administración se atiene al criterio del menor coste económico, subordinando el óptimo conocimiento y difusión del objeto arqueológico y, desde luego, artístico. Este procedimiento lesiona las posibilidades de muchos arqueólogos especialistas, de otros investigadores que no sean arqueólogos, y en ocasiones del propio monumento, lo que resulta más lastimoso.

$\mathrm{Si}$ un arquitecto considerase oportuno proveerse de información antes de actuar, podría solicitar a un historiador del arte que le detallara las intervenciones arquitectónicas anteriores, las partes históricamente más sensibles de una fábrica, la realización de excavaciones pretéritas o las sustituciones de elementos constructivos. Dado que vivimos en una sociedad que se debería esforzar por rentabilizar sus limitados recursos y por incrementar su eficiencia, los responsables de las intervenciones en los edificios históricos harían bien en recurrir a profesionales con el perfil adecuado (historiadores del arte especializados) que les ayudasen en esta tarea de diagnóstico propedéutico. Esos profesionales, además, les proporcionarían un solvente análisis de los criterios y motivaciones que asumieron los autores de la ejecución del conjunto monumental, así como un estudio del uso diacrónico que se otorgó al mismo. En otras palabras, realizarían un examen de algunas cuestiones completamente relevantes.

\section{EL OFICIO DE LOS HISTORIADORES DEL ARTE}

¿A qué se dedica exactamente un historiador del arte cuando estudia edificios históricos? ¿Cuál es su papel en la actual sociedad del conocimiento y, por esa vía, para qué se le necesita? Resulta complejo responder sintéticamente a estas cuestiones y enojoso tener que formular un razonamiento desde una posición defensiva, como si se tratase de una disciplina periclitada y, por ende, injustificada. Pero en la situación actual no podemos seguir haciendo oídos sordos a que otros afirmen que, sobre el campo de estudio de la arquitectura histórica, sus análisis sí son pertinentes, justificados, provechosos, reales y científicos, a diferencia de la HA, que se recrea en el idealismo y la contingencia. Conceder crédito a ese tipo de valoraciones no sólo resulta lesivo para los historiadores del arte. También, y eso resulta más importante, para el conjunto de la ciudadanía.

La reflexión que nos ocupa gravita en torno a un argumento nuclear que parece estar en cuestión: la naturaleza metodológica de la HA, su rigor analítico, la capacidad para contrastar sus planteamientos con indicios, su fiabilidad para formular hipótesis interpretativas y, a la postre, su solvencia para demostrar sus propuestas.

Como en cualquier otra disciplina, existen óptimas HA e HA deficientes. Pero cuando se trata de estudiar 
edificios históricos ningún historiador del arte prudente y ponderado obvia que el punto de partida del análisis debe ser diseccionar la materialidad del propio objeto de estudio. Añadamos nuestro convencimiento, fruto del ejercicio empírico de estudiar templos a pie de fábrica, que la batería de referencias documentales que atestigüen intervenciones y protagonistas - auxilio neurálgico del historiador - siempre debe ser atendida y estipulada de modo que no condicione el examen positivista de la obra. También la HA enseña desde hace décadas que el monumento es el documento prioritario, que en su naturaleza y especificidades físicas se pueden y se deben reconocer los perfiles cardinales de su dimensión histórica. En todo caso, ahí se sitúa nuestro punto de partida, no de llegada.

Todo lo apuntado constituye sólo el fundamento y apertura de nuestro complejo análisis histórico-artístico, tan estético como social, pero en última instancia, cultural en tanto que entramado de logros artísticos, organizativos $\mathrm{y}$ de conocimiento. Más adelante justificaremos con mayor detalle y ahínco esta cuestión, pero dejaremos apuntado un interrogante: ¿se encuentra la ARQ capacitada —más aún, interesada - para razonar la dimensión estética de un edificio histórico? Esa dimensión resulta nuclear -y nunca fortuita- en fábricas concebidas y formuladas para acoger funciones litúrgicas y cultuales, actividades sociales de distinta naturaleza, así como para desempeñar responsabilidades representativas en el plano ideológico.

\section{LOS INTERROGANTES (Y LAS RESPUESTAS) DE LA HISTORIA DEL ARTE}

Cuando ya se ha diseccionado el proceso constructivo y se han estratificado cronológica y materialmente las intervenciones en el mismo, cuando ya se han analizado los materiales y los modos de construir, cuando se han interpretado las fuentes de provisión material de la fábrica y la organización social y productiva que revela, y, más allá, cuando se ha formulado una propuesta paliativa para las eventuales patologías de la construcción, ¿quién informa de las razones ideológicas, espirituales y -en última instancia- culturales por las que el templo o el palacio se construyó con una determinada topografía y no con otra? ¿Quién explica el por qué y para qué de una construcción? ¿Comprender la biografía constructiva de una iglesia permite esclarecer qué actividades se realizaban dentro y a cargo de qué protagonistas? ¿Quién razona las mutantes necesidades funcionales de un recinto sacro en consonancia con la morfogénesis espacial? En fin, ¿quién justifica el espacio y no sólo la carcasa arquitectónica? ¿Quién analiza y explica la semántica y la funcionalidad de los espacios, la articulación de los escenarios y, sobre todo, el arte de crear loci sancti? ¿Quién tiene en cuenta y transfiere al conjunto de la sociedad actual que los escenarios cultuales o políticos carecen de utilidad y significado sin una organización escenográfica y sin unos protocolos rituales? ¿Quién explica que un templo proporciona una puesta en escena para que una comunidad pueda desarrollar en su interior todos los actos ceremoniosos y representativos que le permiten reconocer su identidad y cometido? ¿Quién despliega su lectura del edificio, del texto espacial y monumental, en el contexto histórico y cultural? ¿Quién explica su relación, inequívocamente establecida, con otros espacios?

La HA posee capacidad y autoridad científica para desplegar todas esas respuestas. Sin evasivas, asumimos que esta proposición no es inocua y tiene tantas implicaciones como reivindicaciones (Bourdieu, 1984), pero no son estas últimas las que la motivan. Una aportación fundamental de la HA radica en la capacidad para leer la semiología de espacios concretos, comprender las razones y criterios de la articulación de un recinto y de la creación de lugares en el marco de los espacios interiores ${ }^{2}$. Estos son, a su vez, la razón de ser de la carcasa constructiva (Mañana et alii, 2002: 14-17). La historia de la construcción -los arquitectos- puede diseccionar qué criterios se observaron y qué casuísticas intervinieron en el proceso edificatorio. Pero la construcción es sólo lo que requiere la arquitectura para proveer de recintos a sus usuarios. Ni siquiera examinar la materialidad de los edificios, su dimensión arqueológica, permite comprender el sentido de los ámbitos o las alteraciones de los usos en el seno de una fábrica permanente.

La morfología de las arquitecturas posibilita, pero también impone, modos de ocupar los espacios. Al tiempo, y a la inversa, asigna espacios que deben ser ocupados de un determinado modo por los receptores, aunque se perfilan también espacios más flexibles que posibilitan actividades no regladas. De este modo la arquitectura se erige en un mecanismo de comunicación icónica y espacial, en el mecanismo más eficaz de proyección, presencia y prestigio en el medio social. La arquitectura se alza como el continente que prestigia a los propietarios y las acciones, esto es, a los contenidos. El espacio delimitado arquitectónicamente y ocupado formalmente de manera reiterada logra así explicitar jerarquías sociales («simbolización espontánea del espacio social» decía Bourdieu, 1999: 122. Cfr. Hiller-Hanson, 1984), estructuración mental y crite-

\footnotetext{
2 Sobre espacio y lugar en la edad Media, véase S. Agustín, De diversi quaestionibus octoginta tribus, 20 vs. Vita Cesarii, I: 19. Una reflexión sobre esta temática en Guerreau, 2003.
} 
rios de convivencia y cohabitación ${ }^{3}$. Se consigue, además, especificar los lugares más centrales y, por tanto, más significativos en esa extensión espacial (Brenk, 2010). Lo diremos sintéticamente: la AA estudia e intenta explicar, junto con la historia de la construcción, el arte de alzar edificios, pero no cómo y porqué un simple muro se convierte en obra de arte. La HA, además de interesarse por lo anterior, examina y justifica cómo y para qué se llevó a cabo el arte de crear lugares interiores en un momento y una región determinados.

La HA hace décadas que reflexiona sobre su particular alcance metodológico. Los trabajos de Belting (Belting, 2009) resultaron suficientemente reveladores como para comprender que el Arte -stricto senso- tenía una historia que no se puede retrotraer más allá del siglo XV. Antes de ese umbral existieron imágenes, no "Arte». Las imágenes fueron proyectadas para el empleo cultual, representativo $y$, en menor medida, para la recreación visual. Por esta y por otras razones que sería arduo detallar ahora, la HA se ha ido concibiendo cada vez más a sí misma como una historia de la cultura visual de un determinado estadio histórico del pasado. En un plano análogo, se reflexiona cada vez más sobre la historia de la cultura espacial de un periodo: desde la semiología espacial vigente a la interpretación cultual o política concedida al espacio arquitectónico. Entre los medievalistas esta perspectiva se concentra en el empleo ritual y emocional de los espacios (Baud, 2010). Ciertamente, el estudio de la arquitectura del pasado desde la perspectiva histórica ha ido incrementando sus puntos de interés, basculando de modo decidido sobre el estudio del urbanismo (Arqueología, Patrimonio, 2010). Sin embargo, no se conoce suficientemente bien cómo ocupaban y experimentaban esos espacios cultuales sus usuarios originales y posteriores.

La perspectiva de la HA -de esa historia de la cultura espacial del periodo tardoantiguo y medieval- procura examinar y comprender para qué, y no sólo cómo, se elevó una fábrica. Lo hace porque tiene presente qué es lo que está examinando realmente, en nuestro caso particular, qué es el espacio de culto y qué el espacio sagrado (distintos

\footnotetext{
${ }^{3}$ Lo que determinaba la liturgia eclesiástica, las consuetas, los procesionarios y los penitenciales, que en términos más reflexivos enuncia Bourdieu: «la incorporación insensible de las estructuras del orden social se cumple, en buena medida, a través de la experiencia prolongada e indefinidamente repetida de las distancias espaciales en que se afirman determinadas distancias sociales, y también, más concretamente, a través de los desplazamientos y movimientos de los cuerpos que esas estructuras espaciales, y con ello naturalizadas, organizan y califican socialmente como ascensión o declinación, entrada (inclusión, cooptación, adopción) o salida (exclusión, expulsión, excomunión), acercamiento o alejamiento con respecto a un lugar central y valorizado». Bourdieu, 1999: 122.
}

uno de otro), cómo y por quién se valoraban y se experimentaban. Porque el grave problema de los análisis sintácticos de los espacios es que llegan a enunciar proposiciones ahistóricas o anacrónicas.

El discurso de la HA se fija en un tiempo y un espacio. Hace tiempo que el historiador del arte no es un diletante entre las técnicas arquitectónicas que conocen los historiadores de la construcción, la discriminación de fases constructivas y la documentación escrita. El núcleo del conocimiento histórico-artístico es la comprensión de lo que sucede dentro y fuera del edificio, las razones de ser y no sólo de sostener esa construcción. Sin ese saber que razona las prácticas cultuales, artísticas, litúrgicas que acogieron los espacios arquitectónicos se continuará presentando el patrimonio monumental a la ciudadanía sólo para que lo contemple, pero no para que lo comprenda en su dimensión histórica. Por eso la profesionalidad del historiador del arte redunda en la optimización del conocimiento transferido socialmente.

Un historiador del arte interpreta el espacio que contienen los planos murarios, atendiendo no sólo a la icnografia y la orthografia, sino sobre todo a la escenografía, por emplear términos vitrubianos. Y en este sentido, la valoración y empleo del espacio interior resulta imposible sin el concurso del recubrimiento embellecedor, de la piel ornamentada, que san Isidoro denominó venustas, la tercera y última etapa de todo proceso constructivo, aquella que le dota de una imagen definitiva y completa. Además, nadie dudará de que la arquitectura sea imagen, tanto en su espacio interior como en su proyección volumétrica externa. Atender a esa dimensión icónica resulta fundamental para comprender el alcance ideológico, político o cultual conferido a las construcciones. En una sociedad de la imagen, ¿quién se ocupa de examinar esa dimensión visual, de la iconografía y de la iconología de la arquitectura?

Conforme a lo apuntado, permanecen sin resolver muchas preguntas capitales que pueden ser respondidas de modo idóneo desde la disciplina de la HA. Al declarar esta convicción no pretendemos enmascarar ideológica o epistemológicamente una competencia real entre áreas de conocimiento por los posibles recursos económicos o una relevancia social. Esta pugna existe, sin duda. Pero no es menos cierto que hoy día aún no se abordan cuestiones primordiales. La solvencia analítica de la HA puede y debe revertir en el conocimiento comunitario.

Para reforzar la legitimidad y vigencia de nuestro discurso, los historiadores del arte no necesitamos podar cualquier noción que no sea estrictamente histórico-artís- 
tica. Nuestro utillaje intelectual se nutre de disciplinas colindantes y ajenas entre sí, de las que aprendemos para examinar mejor las imágenes y los espacios. El replanteamiento sistemático y crítico de las bases conceptuales de nuestro saber constituye una tarea abordada por sucesivas generaciones de historiadores del arte. Hemos llegado hasta el presente siendo conscientes de nuestra especificidad, de modo que no requerimos perfilar un campo exclusivo, ni confrontarnos conceptualmente con el resto de las disciplinas. En cambio, sí enfatizamos sin alharacas que ignorar la aplicación práctica de nuestros estudios, omitir la transferencia social de los conocimientos, repercute negativamente en la comprensión y gestión de los bienes patrimoniales (Castillo y Gómez, 2009). Como los investigadores de todas las demás áreas, creemos en la solvencia de nuestro discurso y la relevancia del segmento de saber que proporcionamos a la sociedad. Hace ya tiempo, además, que procuramos perfilar ese discurso para que dispense un beneficio colectivo con la mayor rentabilidad intelectual posible. Con todo, ¿será esta afirmación una de esas proposiciones que sólo alcanzará a aquellos que no necesitaban escucharla porque ya la practican y promocionan? Las disciplinas, lamentablemente, se parapetan tras discursos autorreferenciales. Estos proporcionan corazas pero también obstáculos para conjugar los logros propios con los de otras profesiones, a menudo minimizados.

\section{UN BALANCE PROVISIONAL}

Volvamos al interrogante planteado más arriba: ¡en qué medida interesa o satisface a buena parte de la AA la producción de los historiadores del arte? El estado actual de esta situación puede sondearse examinando los elencos bibliográficos de los estudios referidos a edificios ya estudiados —más o menos adecuadamente, pero estudiados a la postre- por historiadores del arte desde hace décadas, si no un siglo. El balance resulta sorprendente con demasiada frecuencia. Si el desinterés de muchos historiadores es reprobable, la omisión sistemática por parte de algunos arqueólogos no parece la más provechosa de las vías para avanzar en el conocimiento.

La utilización de "canales cerrados de información» por parte de la ARQ (y también por la AA) ya fue denunciada hace mucho tiempo (Ortega y Villagordo, 1999: 10): «La multiplicación de los discursos conduce a la confusión, se anula así el sentido crítico, la capacidad de discernir, de diferenciar lo valioso y significativo del detritus. Ante esto los receptores elaboran, elaboramos, eso creen y creemos, una estrategia de defensa: la especializa- ción. Pero la especialización no es más que una segmentación de las vías de difusión de la información, no es más que la creación de nuevos circuitos cerrados de información». Esa «especialización» descansa fundamentalmente sobre el «control» de la información sobre la materialidad de las estructuras arquitectónicas y, lo que en nuestra opinión es mucho más preocupante, en la omisión de otras disciplinas. Esta desestima se trasluce en algunas publicaciones de ARQ y de AA que debaten como "novedosos" temas ya examinados por la HA hace tiempo, acaso de un modo optimizable, pero abordado a fin de cuentas.

Embarranca el conocimiento argüir — como si se tratara de armas arrojadizas - medidas de sillares contra crónicas abaciales o fórmulas plásticas contra análisis arqueométricos y anchos de galga. Desde nuestro particular punto de vista, como para otros autores (Ripoll y Ripoll, 1988: 426; Reveyron, 2005: 23), sería harto provechoso alcanzar un horizonte de colaboración menos episódico que el actual. Subrayamos de colaboración porque no aspiramos a subordinar o instrumentalizar un método o unas herramientas ajenas, como la valiosa matriz Harris, ni a considerar que la HA pudiera ser un instrumento más de la $\mathrm{AA}$, presunción insostenible.

Como no podía ser de otro modo, buena parte de la HA advierte y estima la objetivación y racionalización que la AA ha introducido en el estudio de los procesos constructivos. A todas luces, la AA ofrece informaciones relevantes y provechosas para el conjunto de la comunidad científica. Sin embargo, resulta innegable que tomar la materialidad del edificio como punto de partida y de destino no resuelve el sentido y propósito cultural, cultual o representativo de la fábrica. Cómo y cuándo se operó son interrogantes básicos; para qué y para quién objetivamente lo son más aún. Y ante la resolución de esos retos se posiciona la HA.

Individuo y disciplina procuran resolver algunas incógnitas y obvian otras. Los distintos sectores profesionales deberán reconocer si intentan dar a entender a las administraciones y a la sociedad que las preguntas abordadas y resueltas por ese colectivo agotan el elenco de cuestiones relevantes para el conocimiento de un objeto patrimonial. Todas las disciplinas han tenido la tentación de trasladar que los asuntos que quedaron fuera de su órbita de intereses y de propuestas epistemológicas resultaban secundarios, e incluso triviales, por el conjunto de la ciudadanía. Tendremos que reconocer si verdaderamente aspiramos a ahondar en el conocimiento histórico o si, arrinconada toda ingenuidad, pretendemos un dominio historiográfico y disciplinar. 
De modo cabal, Quirós afirmaba que «la complejidad y responsabilidad que plantea la intervención en el patrimonio edificado es tal, que no se puede delegar en un solo profesional, en una sola disciplina, la toma de decisiones sobre cómo intervenir» (Quirós Castillo, 2002: 34). ¿¿Son suficientes dos disciplinas? Recientemente se ha intentado reflexionar y sistematizar este interrogante (Caballero Zoreda, 2009: 11-19). Nos tememos que, como en tantos otros casos, la defensa del bien común encubre la reivindicación de ventajas corporativas.

«La arqueología de la arquitectura ofrece un marco conceptual nuevo para superar la situación tradicional de los últimos decenios en el que los estudios de carácter histórico se convertían en un mero apéndice de las investigaciones realizadas de forma previa a la rehabilitación arquitectónica, con frecuencia subordinados a la interpretación global realizada solamente por los arquitectos» (Quirós Castillo, 2002: 34). No podemos estar más de acuerdo con esta legítima reivindicación, ni más en desacuerdo con la intencionalidad que en el fondo la inspira. Se pretende lograr visibilidad a costa de desprestigiar a la HA, sin paliativos. Si la disciplina carga en esta tesitura con el sambenito de subjetiva, idealista y taxonómica, los historiadores serán desplazados reiterativamente. Nos sobran los argumentos que proveen de solvencia, pertinencia y eficiencia nuestra actividad. Y lo demostramos siempre que tenemos oportunidad. Pero las oportunidades hay que reivindicarlas.

Entretanto, las administraciones se contentan a menudo con proporcionar a la sociedad edificios diseccionados, restaurados y rehabilitados. Más raramente se preocupan por instruir, por tratar a sus administrados como personas adultas y críticas, posibilitando con sus actuaciones no sólo mirar y admirar el edificio, sino sobre todo comprender por qué y para qué se operó en su momento aquella fábrica. La HA puede contribuir a formular la respuesta eficiente y solvente a muchas de las cuestiones que una sociedad del conocimiento, crítica y exigente, debe requerir a sus administraciones.

El sentido de las construcciones radica en sus espacios y el de éste en los usos sociales e individuales desempeñados. Es un criterio capital considerar que la arquitectura puede y debe conducir a entender tanto las organizaciones sociales de un periodo como las mentalidades (Ripoll y Ripoll, 1988: 421) y la ideología cultural predominantes en el mismo. Invocar estos dos planos no puede seguir siendo considerado hoy como la contraposición trasnochada del idealismo hegeliano ante el materialismo marxista de Kula, la reflexión conceptual frente a la concreción físi- ca operada en el tiempo y el espacio (Ibid: 424; Ortega y Villargordo, 1999: 8-9). La arquitectura se eleva materialmente para generar ámbitos que alojan y enmarca usos cotidianos y procesos mentales y emocionales. El episteme de la arquitectura medieval se alcanza desde el binomio de la funcionalidad y la representatividad. Leer los muros permite razonar cómo y cuándo se dio cauce a esos porqués.

La HA no idealiza y tipifica la realidad. Ante las fábricas históricas, discrimina el soporte material, describe el proceso constructivo, rastrea el proyecto arquitectónico, justifica la articulación espacial, identifica las atribuciones funcionales y expone las implicaciones ideológicas y culturales (entendiendo estas como el ensamblaje de conocimientos y pensamientos prevalecientes en una sociedad). La HA pretende conocer las aspiraciones y propósitos que contribuyeron a construir la memoria visual y las experiencias espaciales de seres humanos concretos. Este saber se interesa por los promotores y destinatarios, por los custodios y receptores de las imágenes concebidas para lugares $\mathrm{y}$, a la vez, de ámbitos caracterizados por imágenes y protocolos. La fisicidad de recintos y figuras son las evidencias plausibles en las que reconocemos conflictos y pretensiones espirituales, intangibles pero tan o más reales e influyentes que la localización de una cantera o la organización del sistema de trabajo.

\section{Bibliografía}

Arce Sainz, F., 2009: «Historia de Arte, Arqueología de la Arquitectura y el telescopio de Galileo", Arqueología de la Arquitectura, 6,21-29.

Arlaud, C. y Burnouf, J., 1993: L'archéologie du bâti médiéval urbain, Les Nouvelles de l'archéologie, 53-54, automne-hiver, 5-69.

Arqueología, Patrimonio y desarrollo urbano. Problemática y soluciones, 2010, Ayto. Girona-Institut de Recerca Històrica UdG.

Aróstegui, J., 1995: La investigación histórica. Teoría y método, Barcelona, Crítica. Au fil du chantier. Archéologie de la construction au Moyen Âge, catalogue de l'exposition, 1997, CERIAH-Bibliothèque Municipale de Lyon, Lyon.

Azkarate, A., 2008: "La Arqueología de la Arquitectura en el siglo XXI", Arqueología de la Arquitectura, 5, 11-14.

Bango Torviso, I.G., 1996: «Crisis de una historia del arte medieval a partir de la teoría de los estilos: la problemática de la Alta Edad Media», Revisión del Arte Medieval en Euskal Herria, Cuadernos de la Sección de Artes Plásticas y Monumentales, 15, 15-28.

Baud, A. 2010 (ed.): Espace ecclésial et liturgie au Moyen Age, Lyon.

Belting, H., 2009: Imagen y culto. Una historia de la imagen anterior a la era del Arte, Barcelona, [Munich, 1990].

Bourdieu, P., 1984: Homo Academicus, París.

Id. 1999: "Efectos de Lugar", en La Miseria del Mundo, Madrid, Fondo de Cultura Económica, 119 - 124.

Boto Varela, G., 2009: "Morfogénesis espacial de las primeras arquitecturas de San Isidoro. Vestigios de la memoria dinástica leonesa", en Siete maravillas del Románico Español, Aguilar de Campoo, 151-191.

Brenk, B, 2010: The Apse, the Image and the Icon. An Historical Perspective of the Apse as a Space for Images, Wiesbaden.

Brogiolo, G. P., 1988: «L'analisi stratigrafica: un metodo per la lectura delle modificazioni architettoniche», Abacus, 14, 12-15.

Id. 2002: «L'archeologia dell'architettura in Italia nell'ultimo quinquenio (19972001)», Arqueología de la Arquitectura, 1, 19-28. 
Caballero Zoreda, L., 1987: «El método arqueológico en la comprensión del edificio (sustrato y estructura)», in: Curso de Mecánica y Tecnología de los Edificios Antiguos (Madrid 1986), Servicio de Publicaciones del Colegio Oficial de Arquitectos de Madrid, Madrid, 13-58.

Id. 1995: «Método para el análisis estratigráfico de construcciones históricas o 'Lectura de paramentos'", Informe de la Construcción, 435, 37-46.

Id. 1997: «En torno a algunas experiencias de lectura arqueológica de edificios», Quaderns científics i tècnics, 9, 307-324

Id. 2009: «Edificio Histórico y Arqueología: un compromiso entre exigencias, responsabilidad y formación", Arqueología de la Arquitectura, 6, 11-19.

Caballero Zoreda, L., y Fernández Mier, M., 1997: «Análisis Arqueológico de construcciones históricas en España. Estado de la Cuestión", Archeologia dell'architettura, 2, 147-158.

Caballero Zoreda, L., - Arce Saiz, F., y Utrero, Mª de los Á., 2003: «Santa María de los Arcos de Tricio (La Rioja), Santa Coloma (La Rioja) y La Asunción de San Vicente del Valle (Burgos). Tres miembros de una familia arquitectónica», Arqueología de la Arquitectura, 2, 81-85.

Cabrera, J. M., 1983: "Conservación y restauración», en 50 años de protección del patrimonio Histórico-Artístico, 1933-1983, Madrid, 45-53.

Carvajal Castro, A., y De Soto García, Ma de los R., 2010: «Arqueología e Historia. Propuestas para una reflexión conjunta», El Futuro del Pasado, 1, 21-35.

Castillo Ruiz, J., Gómez Jiménez, J.J., 2009: «Propuesta para una reglamentación legal de la actividad profesional de la historia del arte en el campo de la protección del patrimonio histórico», e-rph, 1-15.

Díaz-Andreu, M., 1995: «Arqueología y política: el desarrollo de la arqueología española en su contexto histórico», Trabajos de Prehistoria, 52, n ${ }^{\circ}$, 25-38.

Gabrielli, F., 1996: «La "cronotipología relativa» como metodo di analisi degli elevati: la facciata del Palazzo Pubblico di Diena», Archeologia dell'Architettura, $1,17-40$.

Harris, E.C., 1991: Principios de estratigrafia arqueológica, Barcelona (ed. or. 1979).

Herráez Ortega, M.V. y Teijeira Pablos, D., 2003: «El cuerpo occidental de la iglesia de San Pedro de Arlanza. Propuesta de reconstrucción histórica», De Arte, 2, p. 7-27.

Hiller, B. y Hanson, J., 1984: The social logic of space, Cambridge.

Mañana, P., Blanco, R. y Ayán, X., 2002: Arqueotectura 1: Bases teórico metodológicas para una arqueología de la arquitectura, Tapa - Traballos de Arqueoloxía e Patrimonio, 25, Santiago de Compostela.

Martínez Tejera, A.M., 1993: «De nuevo sobre áreas ceremoniales y espacios arquitectónicos intermedios en los edificios hispanos (ss. IV-X): atrio y pórtico», Boletín de Arqueologia Medieval, 7, 163-215.

Id. 1996: «Dedicaciones, consagraciones y Monumenta consecrationes (siglos VIXII): testimonios epigráficos altomedievales en los antiguos reinos de Asturias y León", Brigecio, 6, 77-102.

Id. 2003: «La arquitectura de la comunidad dimmiyyun (siglos IX-X): 'arquitectura del pacto' y 'arquitectura de resistencia'”, Codex Aquilarensis, 19, 48-72.

Id. 2005: El templo del monasterium de San Miguel de Escalada: «arquitectura de fusión» en el antiguo reino de León (siglos X-XI), Ed. Asociación Española para el Estudio y Difusión del Arte Tardoantiguo y Medieval (AEDATME), Madrid.
Id. 2010: La ecclesia de Peñalba de Santiago (El Bierzo, León). Arquitectura de Fusión' del siglo $X$ en el antiguo reino de León, Ed. Asociación Española para el Estudio y Difusión del Arte Tardoantiguo y Medieval (AEDATME), Madrid.

Id. e.p: «Edilicia cristiana en Conimbriga (Condeixa-a-Velha, Portugal): el conjunto de la domus tanginus», in: J. López Quiroga (Dir.). Conimbriga Medieval. Excavaciones arqueológicas en la 'domus tanginus' (2004-2008), Archaeological Studies on Late Antiquity and Early Medieval Europe (4001000), Archaeological Excavations 2, British Archeological Reports, Oxford.

Id. (2008-2009) inédito: Proyecto Científico y Estudio Histórico del monasterio de San Miguel de Escalada (Gradefes, León), IV Vols., financiado por la Junta de Castilla y León.

Moreland, J., 2001: Archaeology and Text, Londres.

Ortega Ortega, J. y Villargordo Ros, C., 1999: «La arqueología después del fin de la arqueología, Complutum, 10, pags. 7-14

Parenti, R., 1995: «Historia, importancia y aplicaciones del método de lectura de paramentos", Informes de la Construcción, 435, 19-29.

Parenti, R., 1996: «Individualización de las unidades estratigráficas murarias», en Caballero, L. y Escribano, C. (eds.): Arqueología de la Arquitectura. El método arqueológico aplicado al proceso de estudio y de intervención en edificios históricos, Salamanca, 75-86.

Pierotti, P. y Quirós, J.A., 2000: «Archeologia dell'architettura e storia dell'architettura: due disciple a confronto», Atti del II Congresso Nazionale di Archeologia Medievale, Brescia, 377-380.

Quirós Castillo, J. A. 1996: «Indicadores cronológicos de ámbito local: cronotipología y mensiocronología», en Caballero, L. y Escribano, C. (eds.): Arqueología de la Arquitectura. El método arqueológico aplicado al proceso de estudio y de intervención en edificios históricos, Salamanca, 179-187.

Id. 2002: "Arqueología de la Arquitectura en España», Arqueología de la Arquitectura, 1, 27-38.

Reveyron, N, 2000: «Les nouvelles approches de l'architecture médiévale, Les dossiers d'archéologie. Comment construisait-on au Moyen Âge?, n²51, 4.

Id. 2005: Chantiers lyonnais du Moyen Age, Archéologie et histoire de l'art, Documents d'Archéologie en Rhône-Alpes-Auvergne.

Ripoll, O. y Ripoll. G., 1988: «Los conceptos de arqueología e historia del arte antiguo y medieval; apuntes historiográficos», Espacio, Tiempo y Forma, Serie II, H.» Antigua, t. I, 1988, 411-426

Sapin, Ch., 2003: «Archéologie de l'architecture carolingienne en France. État de la question", Hortus Artium Medievalium, 8, 55-70.

Vela Cossío, F., 2007: «Intervenciones en edificios y conjuntos históricos. Arqueología de la Arquitectura», Actas del I Congreso de Patrimonio Histórico de Castilla-La Mancha «(La Gestión del Patrimonio Histórico Regional. Homenaje a Victoria Cabrera Valdés»), Editores científicos Mar Zarzalejos Prieto, Miguel Ángel García Valero, Luís Benítez de Lugo Enrich (Valdepeñas 2004) Ciudad Real, T. I, 157-173.

Recibido: 9 de julio de 2010 Aceptado: 15 de noviembre de 2010 